\title{
Developmental characteristic of primary schoolchildren: traditional educational program or developmental one?
}

\author{
Ekaterina Ruslyakova*, and Leysan Slobozhankina \\ Nosov Magnitogorsk State Technical University, Russia
}

\begin{abstract}
The following article presents a longitudinal research of mental state and intelligence of primary schoolchildren following different educational programs. Nowadays education in Russia has been undergoing lots of changes. New systems, methods and technologies for teaching children in primary school are being introduced. Therefore, children often display a high level of anxiety and school neuroses. So the problem of mental state of primary schoolchildren associated with the issues of education, upbringing, and development of junior schoolchildren becomes more urgent. Educational programs that take into account the mental state of children are able to improve health, social adaptation and their mental and personal development. Our empirical study has proved the hypothesis, which asserts that there are differences in children following different educational programs: "School of Russia" and "Perspective Primary School", their mental state and intellect are also different.
\end{abstract}

\section{Introduction}

Russian education has been undergoing rapid changes lately, new systems, methods and technologies for teaching children in primary school are appearing. Due to these changes, some children often suffer from higherthan-normal anxiety levels and school neuroses. Therefore, the problem of the mental conditions of primary schoolchildren associated with the issues of education, upbringing and development of primary schoolchildren becomes more urgent. Training programs that take into account the children's mental state are able to improve their health, social adaptation and mental development of their personalities. This will be the reserve for improving the process of learning and reaching the goals and objectives of the primary educational program.

Many parents have been concerned about primary school education currently. They are worried whether their children will be able to fulfill the requirements given by the primary educational program [1].

\section{Methodological Framework}

Nowadays there are two systems of teaching children in primary school: traditional and developmental. Each system has its own programs. The traditional programs include: "Primary School of the 21st Century", "School 2100", "School of Russia", "Harmony", "Perspective Primary School", "Classical Primary School", "The Planet of Knowledge", "Perspective", etc. Developmental system includes two programs: the program of L.V. Zankov and the program of D.B. Elkonin, V.V. Davydov and others [2, 3, 4].

In this regard, many parents and teachers are concerned about the question of teaching primary schoolchildren, whether they will be able to meet the requirements set by the school curriculum, whether its content is accessible and safe for them.

The aim of this research is to study mental state and intelligence of children of primary school age, who are following different educational programs.

The object of the research is primary schoolchildren (1st grade pupils and then 2nd grade pupils) studying according to the educational programs: "School of Russia" and "Perspective Primary School".

The subject of the research is mental state and intelligence of children of primary school age.

Hypothesis: there are some differences between the mental state and the intellect of children following different educational programs: "School of Russia" and "Perspective Primary School".

In the research the following methods were used: a) theoretical - review and analysis of literature, b) empirical - diagnosis, qualitative and quantitative analysis of results, c) mathematical - using statistics of pair samples, descriptive statistics, Student's T-test for independent samples [5].

In this study, we used the following diagnostic materials: [6];

1. Child test anxiety (R. Temple, M. Dorca, V.Amen)

2. Color-picture test (A.O. Prokhorov, G.N. Gening) [7];

3. Color progressive matrix of J. Raven [8].

* Corresponding author: ekaterina-ruslyakova@yandex.ru 
In order to perceive any information given by the teacher easily and more productively, a child needs not only to have sufficient mental development, but also to be in a certain, prosperous mental state. The combination of these components contributes to learning. One of the main conditions for successful teaching and educational work is the need for the teacher to take into account the age, mental and physiological characteristics of schoolchildren and an individual approach to students.

Unfortunately, today the mental state of children during the process of learning is less studied than the processes and properties. But, nevertheless, there are useful researches of many psychologists [9, 10]. G.N.Gening (Candidate of Science (Psychology), Kazan State University) and A.O. Prokhorov studied the mental state of children of primary school age (Prokhorov, Gening, 1998: 42).

It is very important for both the parent and the teacher not only to be attentive to the level of the child's development, but also to understand the state that is the child undergoing at the moment.

For our longitudinal study, we took primary schoolchildren. Since our study was longitudinal, we have been studying students from the 1 st to the 2 nd grade of schools № 6 and № 16 in Magnitogorsk. The age range of children of the 1st grade was 6-7-8 years old, of the 2 nd grade it was 7-8-9 years old. The number of the children engaged in the experiment was 52 people from the 1st grade, and 89 people from the 2 nd grade. We also took two additional groups with the same educational programs as at the beginning of the study. The experiment was carried out twice in the school year. In both groups, we held an autumn testing at the beginning of the school year, and the spring testing was performed at the end of the school year.

\section{Results and discussions}

In Russia there are two systems of teaching children in primary school: traditional (the edict of the Ministry of Education and Science of the Russian Federation from 21.10.2004 №93) and developing (the system of Zankov, the system of Elkonin-Davydov). Each program has its characteristic features. This article does not intend to decide on which program is the best. Any program considers a particular mindset, perception properties and intellectual processes of a child.

Within one school children in different classes may follow different educational programs, but more often the school selects one program to carry out in the school. After graduating from the primary school, children receive an equal volume of knowledge determined by the state standard of education. The advanced material, which can be taught as additional lessons for children, can be included in the curriculum regardless of the kind of the educational program. Besides those programs, there is a variety of authentic, interschool, experimental systems, which are not considered in this research.

All traditional programs have a required minimum of knowledge and unified aims, tasks, principles and contents. Their main difference is in the organization of the learning process and the presentation of the material.

The system of primary education of L.V. Zankov is a developing program for the primary school created in 1995-1996. The aim of the program is general development of the learners, the development of their intelligence and will as a foundation for acquiring knowledge, abilities and skills. The main tasks include the volume of knowledge and the unfolding of a learner's personality, comprehensive development of each learner, as opposed to bringing all students to the same level of knowledge. The two pillars of the program are independence and creativity, the knowledge is not given directly, it should be discovered in process. This is what makes this program different from the traditional one, where an example is given for children to reproduce it, make conclusions and do exercises to practice. The difficulty level of Zankov's program is high; it consists mostly of theoretical knowledge based on the understanding of the systematical interconnections. Emphasis is put on error correction and conscious learning process. The program teaches to work at a rapid pace, look for information and solutions independently, as well as self-reflection and application of a creative approach to problem solving.

On the contrary, the system of primary education of D.B. Elkonin - V.V. Davydov sticks to a moderate pace: "Slow and steady wins the race" - it is aimed at in-depth knowledge. This program is developing, not traditional. This program has the most balanced inner structure. In spite of the fact that it was created in 1960-1970s, it harmonizes perfectly with the concept of modern education in Russia. The term "developing program" was introduced by V.V. Davydov. The aim of the program is to form a system of scientific terms, independence, initiative, the ability to think out of the box. It forms the ability to analyze contents, plan, find unified principles, and evaluate oneself and others critically. It develops the ability to work in an unfamiliar situation, become aware of what one knows and does not know, the ability to express one's view without considering it the only correct opinion, the attention to details, the ability to generalize, creative thinking and logic. If a learner's judgement is uncommon, it is not a mistake, but an opinion. What is being evaluated here is not knowledge, but the effort and self-assessment precedes the assessment of the teacher. The type of relationship between the learner and the teacher is cooperational. The education starts with substantivepractical activity, from the general to the specific. Overall, the program is very different from the others and it works better when followed from the $1^{\text {st }}$ to the $11^{\text {th }}$ grade.

The educational program for primary school 2100 under the editorship of A.A.Leontyev (school 2000, Peterson program) is one of the most popular contemporary programs and based on traditional principles. The main aim of it is successful integration in society. Its tasks include forming the skills for further productive working life; preparation to further lifelong learning; domination of scientific humanitarian view of the world; general cultural development; socio- 
psychological adaptation; creative development. On the one hand, this program strives to develop the individuality and on the other hand, to help the learners adapt to constantly changing society. The main principle is the comprehensive and continuous development, formation of the image of the world, conscious attitude to the world. Each stage of education correlates with age-specific properties of a child's psyche. Being a traditional program, it is aimed at an average learner and average level of knowledge.

The educational program "The School of Russia" (Pleshakov) - primary school of the Soviet period. Traditional program. The core of the program is spiritual and moral development of Russian citizens, teaching and educational activity. Its tasks include development of humane personal qualities of a child, such as tolerance, kindness, responsibility, compassion, willingness to help others, motivation to study, conscious learning, and skills to maintain health and safety of life. The fundamental principle of the program is reliability, stability and the openness to the new. Problem-solving approach to education. No special qualities are required from the child, which makes this program easy to apply even to the least prepared children.

The educational program for primary school "Harmony" (N.B. Istomina) is a traditional program based on the key ideas of Zankov's program adapted by a professional teacher Istomina. The aim of the program is comprehensive development of the child, comfortable education. The program tries to reconcile the traditional approach to the developing one. Being a traditional program, it does not require any special abilities from the learner. It helps develop self-control, productive communication of the children with each other and with the teacher. It teaches to determine causal connections.

"Primary school of the XI century" is a traditional education program for primary school under the editorship of Vinogradova, which aims at comfortable education of the child. The education process is organized in a way that each learner could feel successful and work in accordance with their own pace. The main principle is natural or biological and urges to take into consideration important needs of the child: curiosity, communication, diverse productive activities. In the process of education an important role is given to individual approach, research, mild adaptation and prolonged preparation period before any kind of activity.

"Perspective primary school" is a traditional contemporary educational program, which strives to guarantee well-balanced development of children in accordance with their personalities. The learner can take on the role of a teacher and even the role of the organizer of the educational process. The classwork is often carried out in small groups. The tasks have different level of difficulty. The education anticipates the development and is placed in the "area of the nearest stage of development" of the child. If the task is to difficult for the child, another learner from the group can offer help. Understanding, development and education unfold in the collective process. Different forms and techniques of representing the tasks, the differences in levels and teamwork offer a range of perspectives for individual development of a child.

The program "Perspective" is another traditional educational program for primary school created basing on contemporary studies in pedagogics and psychology in conjunction with the best traditions of usual education. The program is aimed at a comprehensive development of the personality taking into account agespecific features, interests, needs and personality of every child. Development of communication skills, of the ability to listen and understand the question, to express ideas and interact verbally is of great importance. The program pays great attention to the use of symbols to model objects and correlations between them, to developing logical and abstract thinking, analysis and synthesis.

In the hands of a professional, any technique and any program can be used successfully to achieve educational objectives.

Our empirical study has proved the hypothesis, which confirms that there are differences between children studying different educational programs: "School of Russia" and "Perspective Primary School", between their mental state and intellect.

According to the data obtained by the methods used in the course of the research, we obtained the following results for each educational program:

1. Students of the first grade studying educational program "School of Russia" scored high, but there were no significant differences between them and those from the second grade, where they demonstrated a positive dynamics in the mental state improvement. Some of the most manifested states are: friendliness, benevolence; attention, concentration; joy and sincerity. According to the anxiety test, the students also showed improvement, which increased by $4.59 \%$ and initially showed a high level during the study period, but there were no significant differences in the increase of anxiety. The colored progressive matrices of J. Raven showed us negative trends of the intellectual sphere by the end of each year of training, which is due to natural factors influencing mental work and our research has proved that such differences are significant.

2. Students of the educational program "Perspective Primary School" also showed us improvement in mental state and such differences are significant, there are the same prevailing states as those of the students of the School of Russia: friendliness, benevolence; focus concentration; sincerity. The expressed in the first grade "joy" was replaced by "dream", "fantasy". Thus, the students of the "School of Russia" experience "joy" more often in the 2nd grade, and the pupils of the "Perspective Primary School" experience a state of dreaminess. The anxiety test also showed us the increase of anxiety, and it has significant differences, which during the research increased by $6.12 \%$, which is slightly higher than of the students of the "School of Russia" and is also based on initially high levels. According to the test of J. Raven, color progressive matrices, we can also observe a decrease in the intellectual sphere of pupils at the end of the school year that is also different. 
3. In general, over the two years of the study, we can see that the intellect of students studying both programs has slightly decreased, but the students of the "School of Russia" did not demonstrated as much decrease as the students of the "PPS" program. An anxiety level in both programs is high, but the "SR" program again shows us that anxiety in group has grown not so much as in the case of students participating in the "PPS" program. The students of both programs see dynamics in terms of mental state, but the students of the "SR" program display their mental state more vividly than the students of the "PPS" program, so it can be assumed that the traditional educational program has a better impact on primary students.

\section{Conclusion}

In order to draw definitive conclusions, we must study the mental state and the intellect of the children studying definite programs in more detail. It would be more productive to conduct such an experiment throughout the entire course of primary education, from the first to the fourth grade, and then, according to the results of the research, we would be able to identify which of the programs influences children more favorably.

Nowadays, in pursuit of new learning technologies, we often do not take into account those nuances that would help our children to perceive new complicated message that teachers try to deliver to them more easily. In order to make it easier for the child to respond the information given by the teacher, the child needs not only mental development, but also that mental state that promote learning, which are combined, so that the same mental activity, the states play an essential role in the activity and behavior of a person, especially a schoolchild. One of the main conditions for successful teaching and educational work is an individual approach to the students, since the mental state is the basic accompaniment for their education [11]. Many factors influence changes in the mental state: disagreements in the family, the attitude of the teacher, the relations with classmates, the understanding of the school material and many other things all combine to give the child the state or mood in which he performs all his educational activities [12]. It is also necessary to take into consideration age-related features of school age with their own characteristics.

Our empirical research has proved the hypothesis put forward by us, which confirms that there are differences between children studying different educational programs: "School of Russia" and "Perspective Primary School", between their mental state and intellect.

Autop expresses deep gratitude to his teacher and professional mentors, Mamaichuk Irina Ivanovna, Professor of St. Petersburg State University; Makhnevoy Lyudmila Andreevna, doctor of the highest category, Children's polyclinic No. 6, Magnitogorsk; Musiychuk Marina Vladimirovne, Professor of Nosov Magnitogorsk State Technical University, Russia.

\section{References}

1. I. V. Reutskaya, , R. V. Savkina, E. E. Ruslyakova, L. V. Mezentseva, O. V. Gribova, International Journal of Applied Business and Economic Research 15(11), 255-263 (2017)

2. D. B. Elkonin, Selected psychological works (Moscow: Pedagogics, 1989)

3. V. V. Davydov, Questions of Psychology 1, 13 18 (1992)

4. T.A. Ratanova, O.V. Nesterova, Questions of Psychology 5, 39-43 (2012)

5. G. Domino, M. L. Domino, L. Marla, Psychological Testing: An Introduction (Cambridge University Press, 2006)

6. V. Amen, M.Dorca, R. Temple, Child test anxiety, Workshop on age psychology (Saint Petersberg, Rech, 2002)

7. A.O. Prohorov, G.N.Genning, Questions of Psychology 4, 42-53(1998)

8. J. Raven, Cognitive Psychology, 1 (41), 1-48 (2000)

9. A. K. Pashchenko, Cultural and historical psychology 3, 78-85 (2010)

10. A. Z. Zack, Questions of Psychology 5, 146$151(1981)$

11.E.E. Ruslyakova, The European Proceedings of Social \& Behavioural Sciences EpSBS, 844-850 (2017)

12. L.F. Bayanova, E.A. Tsivilskaya, R.M. Bayramyan, K.S. Chulyukin, Psychology in Russia: State of the Art 4, 94-105 (2016) 